Time as a barrier to evidence uptake

Time as a barrier to evidence uptake - A qualitative exploration of the concept of time

for clinical practice guideline uptake by physiotherapists

Jessica Stander ${ }^{\mathrm{a}}$, Karen Grimmer ${ }^{\mathrm{a}}$, Yolandi Brink ${ }^{\mathrm{a}}$

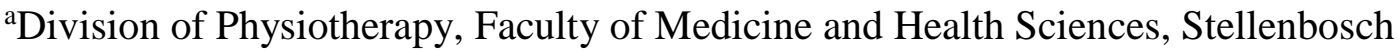

University, Francie van Zijl Drive, Tygerberg 7505, Cape Town, South Africa

Corresponding Author:

Jessica Stander

Division of Physiotherapy, Faculty of Medicine and Health Sciences

Stellenbosch University

Francie van Zijl Drive, Tygerberg

Cape Town, South Africa

Tel: +61424851751

Email: jessicas@sun.ac.za

Karen Grimmer email: grimmerk@sun.ac.za

Yolandi Brink email: ybrink@sun.ac.za

This is the author manuscript accepted for publication and has undergone full peer review but has not been through the copyediting, typesetting, pagination and proofreading process, which may lead to differences between this version and the Version of Record. Please cite this article as doi: $10.1111 /$ jep.13397

This article is protected by copyright. All rights reserved. 


\title{
Time as a barrier to evidence uptake - A qualitative exploration of the concept of time for clinical practice guideline uptake by physiotherapists
}

\begin{abstract}
Background: Lack of time has consistently been reported as a major barrier to effective research evidence-uptake into clinical practice. There has been no research to our knowledge that explores time as a barrier within the Transtheoretical model of Stages of Change (SoC), to better understand the processes of physiotherapists' uptake of clinical practice guidelines
\end{abstract} (CPG). This paper explores the concept of lack of time as a barrier for CPG uptake for physiotherapists at different SoC.

Methods: A 6-step process is presented to determine the best-fit SoC for 31 physiotherapy interviewees. This process used an amalgamation of interview findings and sociodemographic data, which was layered onto the SoC and previously identified time-barriers to CPG uptake (few staff; high workload; access to CPGs; evidence-based practice as priority in clinical practice; “time is money” attitude; and knowledge on the use of CPGs).

Results: The analysis process highlighted the complexities of assigning individuals to a SoC. A model of time management for better CPG uptake is proposed which is a novel approach to assist evidence implementalists and clinicians alike to determine how to progress through the SoC and barriers to improve CPG uptake.

Conclusions: To the authors' knowledge, this is the first attempt at exploring the construct of (lack of) time for CPG-uptake in relation to the physiotherapists' readiness to behaviour 
change. This study shows that 'lack of time' is a euphemism for quite different barriers, which map to different stages of readiness to embrace current best evidence into physiotherapy practice. By understanding what is meant by 'lack of time', it may indicate specific support required by physiotherapists at different stages of changing these behaviours.

Key words: Clinical practice guidelines; Barriers; Physiotherapy; Knowledge translation

\section{Background}

Clinical practice guidelines (CPGs) are defined as "a convenient way of packaging evidence and presenting recommendations to healthcare decision makers” (p.6) ${ }^{1}$. Thus CPGs, in theory, should provide busy physiotherapists (PTs) with easy-to-use tools that support efficient access to current best evidence in ways that inform their daily clinical practice decisions. However, CPG uptake rarely occurs at the speed of evidence production ${ }^{2}$. Knowledge translation strategies, specifically training programmes about evidence-based practice (EBP) and CPGs, aim to support PTs' evidence-uptake behaviours and their use of CPGs to leverage effective and efficient practices ${ }^{3,4}$. This aligns with the six domains of healthcare quality: safe, effective, patient-centred, timely, efficient and equitable ${ }^{5}$. These six domains ensure optimal patient management.

Lack of time has consistently been reported as a major barrier to effective uptake of research evidence into clinical practice ${ }^{6-10}$. Despite this body of evidence, the concept of a "lack of time” is not well understood, as this concept may refer to different underlying reasons in different contexts ${ }^{10,11}$. Furthermore, there are few effective strategies available for clinicians to assist them to decrease time-use barriers and improve time management skills for research 
evidence uptake ${ }^{10-12}$. Other barriers to EBP in PT include lack of resources, lack of skills to access and understand research evidence, misperceptions of EBP, lack of managerial support, lack of generalisability of research and what constitutes quality evidence ${ }^{6,7}$.

Prochaska and DiClemente's Transtheoretical Model (TTM) of Stages of Change (SoC) is one of the oldest behaviour change frameworks, developed to describe health choices and stages of health behaviour change (Figure 1$)^{13}$. The TTM was initially developed for managing substance abuse, specifically smoking cessation ${ }^{14}$, and it has since been applied to changing dietary behaviours ${ }^{15}$ and physical activity ${ }^{16}$. The TTM has more recently been applied to investigations into the effectiveness of interventions into healthcare professionals' (physicians, nurses, allied health practitioners) uptake of evidence into practice (in this case healthcare worker's hand hygiene), with greater compliance with uptake of evidence being related to higher levels of SoC ${ }^{17}$.The authors indicated that to understand the complexity of behaviour change related to CPG uptake, the healthcare professionals' readiness to change needs to be considered, as it cannot be assumed that all healthcare providers are similarly motivated to embrace EBP ${ }^{17}$. SoC comprise pre-contemplation (no recognition of need for or interest in change); contemplation (thinking of changing); preparation (intention and first steps towards taking action to change); action (adopting new behaviours); and maintenance (ongoing practice of new behaviours) ${ }^{18}$. There is also a "termination" phase that is used in substance abuse literature that is usually not referred to in implementation science, as it is not relevant due to the focus of continual quality improvement in EBP uptake practices ${ }^{14,17}$. 
>>Figure 1: Prochaska \& DiClemente's Stages of Change (adapted with permission) about here $>>$

There has been no research to our knowledge that explores time as a barrier within the SoC framework, to better understand the processes of PTs' uptake of CPGs. We postulate that understanding barriers to CPG uptake within the context of changing EBP behaviours is a 'chicken and egg' situation, where barriers to behaviour change, and PTs' SoC are related to their understanding of CPGs. If the PTs understand how to use CPGs in practice, they may be more inclined to overcome barriers to CPG uptake. This paper explores the concept of lack of time as a barrier for CPG uptake for PTs at different SoC.

\section{Methods}

Detailed descriptions of the methods underpinning this qualitative study were published previously ${ }^{11}$. These methods are summarised below.

Reporting framework: The Standards for Reporting Qualitative Research (SRQR) were followed to ensure a rigorous reporting process of the study findings ${ }^{19}$. The SRQR checklist is provided in Additional file 1.

Ethics: Ethics approval was received from the Health Research Ethics Committee of Stellenbosch University (S17/05/100). Written informed consent was obtained from the participants via an online form. All research team members were familiar with the South African context in which this study took place and were experienced in the conducting and reporting of qualitative research.

This article is protected by copyright. All rights reserved. 
Sample: The participants were South African PTs from private, public or educator sectors (considered for analysis purposes as three independent clusters) needed to be registered with the Health Professions Council of South Africa (HPCSA). PT clinicians had to be practicing PT for at least 25 hours per week in any field of PT. PT educators not actively treating patients, had to be involved in undergraduate or postgraduate PT teaching. The email list obtained from the HPCSA, was randomized, and groups of 30 participants were contacted at a time. A total of 473 public and private PTs was invited. Eighty-three PT educators were contacted in a parallel process ${ }^{11}$.

Data collection and saturation: Semi-structured individual interviews were conducted, audiotaped, and independently transcribed ${ }^{11}$. The question relevant to this paper was: "When considering your workload, is it easy or difficult to integrate CPG into your clinical load?” This question explored whether the participants perceived CPG utilisation in practice as adding to or decreasing their clinical workload. In the previously published paper ${ }^{11}$, the main theme that emerged from this questions was "lack of time”, with the subthemes being: few staff; high workload; access to CPGs; EBP as priority in clinical practice; "time is money” attitude; and knowledge on the use of CPGs. Interviews continued with PTs in each cluster until no new information was obtained in consecutive interviews.

Data analysis: For the purposes of this paper, an inductive thematic content analysis approach was taken where the transcript content was analysed by hand, and the themes emerged from the analysis of the relevant question ${ }^{20}$. Data analysis followed an iterative process of data immersion and familiarization; theme identification; creating a codebook, 
data coding and categorizing; data mapping and interpretation, and then checking the findings against the original transcripts ${ }^{20}$.

Establishing credibility: Member checking of transcriptions were performed by 28 of the 31 participants (three participants did not respond to requests to do this) ${ }^{21}$.

Researcher bias: The interviewer was a practicing PT clinician and educator. She could relate to the participants and analyse the data within her understanding of South African PT practice. She brought a recognized bias to the process of analysis of the interviews in that she is enthusiastic about providing best-evidence PT care, and teaching PTs about CPGs. The bias was limited through following a process of phenomenological reduction, whereby the researchers "interpreted the data with a critical stance, while attempting to restrict their own interpreting beliefs and subjectivity” ${ }^{11}$.

Determining SoC classification: There is currently no way of establishing participant's SoC for evidence uptake, thus the need arose to categorise in the following manner. The best-fit SoC for each interviewee was determined using an amalgamation of interview findings and socio-demographic data, which was layered onto the Transtheoretical model of the SoC ${ }^{18}$. The following steps were followed (See Figure 2):

1. JS assessed whether the participants could provide a definition of CPGs that aligns with recognised and published definitions and whether they believed that CPGs were of benefit to the PT profession. This was achieved by comparing the definition of CPGs according to Treweek et al. ${ }^{1}$ with the definition that each participant provided. The participants' answers were divided into Clear or Unclear understanding of CPGs;

This article is protected by copyright. All rights reserved. 
2. Participants' views (positive or negative) were explored to determine whether the use of CPGs added to, or reduced, their workload, and whether PTs perceived CPGs in their clinical practice as beneficial (or not), and overall to the PT profession.

3. A preliminary allocation into a SoC category was made for each participant, by comparing participants' understanding of CPGs, and their views on benefits, with the definition for each level of the SoC model.

4. Exemplar quotations from the full interview transcript on understanding, uptake and benefits of CPGs were identified as an independent source of evidence for the preliminary categorisation;

5. Differences in socio-demographic data (sectors of employment, years since graduation, and gender) were then determined for each SoC.

6. The authors discussed and agreed on the final SoC categorisation for each participant.

>>Figure 2: Process of Stages of Change allocation about here>>

\section{Results}

Participants: Thirty-one PTs participated in the study: 10 participants in private and public practices each, and 11 participants from the education sector. The response rate for the PT clinicians and educators were $4.2 \%$ and $13.3 \%$ respectively. SoC classification: Table 1 outlines the classification of study participants into their appropriate SoC and includes illustrative quotations in relation to their appropriate SoC. Some participants did not have a clear understanding of CPGs, and of those that did, not all 
were ready to implement CPGs into practice. Conversely, of those individuals who were unclear about CPGs, there were some who wanted to apply best evidence to their practice and were unsure about doing this. Years in practice were not an indicator to whether the person was more or less likely to implement CPGs in their practice.

>>Table 1: Classification of study participants into Stages of Change about here>>

To be classified at the Pre-contemplation stage, participants must have provided evidence that they were not ready to explore the use of CPGs in clinical practice. If participants provided evidence that they were considering the possibilities of implementing CPGs, then they were classified as in the Contemplation stage. If participants noted the benefits of using CPGs in clinical practice, or if they understood what CPGs entailed, or had previously used them, they were assigned into the Action stage. P6 and P11 did not see accessing of CPGs as a barrier to CPG uptake, but rather assisting them due to it being readily available to them via online sources. They may be classified at the Action stage of the SoC, as they can already see ways to incorporate CPGs as part of their clinical load. They will need assistance with choosing a CPG and prioritising conditions seen in practice for application of CPGs. To be classified at the Maintenance stage, the participants must have provided evidence that they have successfully used CPGs and are continuing to use it.

However, when assigning participants into the TTM SoCs, there were complexities in the classification process. Considering the quotations related to whether "time due to workload" 
was an issue for CPG uptake, the answers were initially divided into "yes “, "no” and "do not know” groups. In the “yes” group there were five private, two public and two educators that indicated time as a barrier. These participants were classified in the lower SoC (Precontemplation $(\mathrm{n}=5)$ and Contemplation $(\mathrm{n}=3)$ ), except one participant who was classified as Maintenance. One private PT, two public PTs and five educators did not think that time was a barrier to CPG uptake. All but one of the PTs that did not identify time as a barrier were classified in the higher SoC, Action ( $n=6)$ or Maintenance $(n=1)$. The one participant (P07) that was ultimately classified as "Preparation” reflected more on the view of the public sector PT than their own position. In the "do not know" group four private, six public and four educators were identified.

When comparing the different SoC levels to the subthemes relating to the concept of "lack of time” (Figure 2), all participants identified “EBP as priority in practice” as a factor, while certain SoC levels were more likely to identify other subthemes of the "lack of time”. For example, the participants in the pre-contemplation stage, were more likely to identify "Few staff, high workload” as barriers to CPG uptake. In addition to above, participants in the contemplation stage identified “accessing CPGs” as another barrier. Whereas, participants in the preparation stage, identified “Time is money” as barrier to CPG uptake. Participants in the action stage identified "knowledge on CPG use" as a barrier. The maintenance stage had no barriers apart from “EBP as priority in practice”, being cited more as a factor influencing rather than a barrier to CPG uptake. 
The authors conceptualised a model of time management for better CPG uptake (Figure 3). This model combines the barriers of time, the different SoC ${ }^{18}$ and the six domains of healthcare quality ${ }^{5}$. This model gives researchers a way of categorising individuals into different SoC to assist clinicians in CPG uptake to ultimately align clinical practice to evidence-informed practice. Central to the model is the barrier of time, with the first circle providing underlying challenges to the concept of "lack of time" for evidence uptake. The following circle deals with a clinician moving through the different SoC (from Precontemplation to Maintenance) to reaching the criteria for healthcare quality. The model is encompassed by the clinician determining the importance of the outer circle, "EBP as priority”, to their own clinical decision-making process. Each circle within the wheel model is a moving part, with the circles' parts aligning and interacting with each other at different stages of their process toward optimum usage of evidence as part of their decision-making process.

The authors mapped the constructs of the wheel model (Figure 3) to the Theoretical Domains Framework of behaviour change (TDF) (Table 2) to support its design and applicability to addressing the lack-of-time barrier to CPG uptake ${ }^{22}$. The updated TDF “provides a method for theoretically assessing implementation problems, as well as professional and other health-related behaviours as a basis for intervention development" ${ }^{23}$. The TDF has previously been used to investigate influences on health and clinical behaviours, developing and evaluating implementation intervention designs and guiding appropriate behaviour change technique identification ${ }^{22}$. 
>>Figure 3: Wheel model of time management for better CPG-uptake about here>>

>> Table 2: Mapping of wheel model to Theoretical Domains Framework ${ }^{22}$ about here>>

\section{Discussion}

The complexity of classifying individuals into different levels of readiness to change, indicated the importance of understanding each participant at their level of readiness to “hear” about CPGs. This understanding may lead to more targeted interventions to train PTs about EBP and using CPGs as an efficient source of information, which may in turn lead to sustainable long-term behaviour change in CPG uptake ${ }^{17}$. The importance of EBP in clinical practice was echoed by all the SoC, showing that this is may be a strong motivator for CPG uptake, if the underlying reasons for a "lack of time" can be effectively addressed. The fact that both the Pre-contemplation and Contemplation participants identified logistical issues (“few staff, high workload”, “accessing CPGs”), links to a limited understanding of the function and benefit of using CPGs in practice. It is interesting that the Preparation participants were focused on what the monetary effect would be to CPG-uptake, possibly indicating that they may benefit from understanding the domains of healthcare quality to support its use to improve healthcare outputs ${ }^{5}$. The Action participants may benefit from a deeper understanding to determining the quality of the CPGs, including the strength of the underlying research that the CPGs drew from. The Maintenance participants are in a unique position to become change agents to increase the use of CPGs among colleagues and the greater healthcare community, as they already interact with and use CPGs in their daily 
practice. The five educators that did not perceive time as a barrier, may think that they are able to use CPGs easier because they are used to working with research documents and can readily access CPG as part of their teaching role. Conversely, this may also indicate that the educators do not understand the practicality of engaging with CPG above what is expected of clinicians in a daily workload.

The model of time management for better CPG uptake (Figure 3) proposes a novel approach to assist evidence implementalists and clinicians alike to determine how to progress through the SoC and barriers to improve CPG uptake. When clinicians can identify their level of readiness to use CPGs, then they are able to choose the strategy to enable moving forward and improve or maintain their CPG-uptake. The strength of the proposed model is that it provides guidance on how to move an individual through the different SoC by determining where their SoC lies in relation to their perceived barriers to CPG uptake, but also considering the criteria for healthcare quality. This ensures a growing ability of clinical decision-making in light of the best available research evidence. A weakness of this model is that it may still not address the fluidity of readiness to change with regards to individuals moving forward and backward between SoC, while experiencing different barriers to optimum CPG uptake. The model may not account for all cultural differences; however, the identified barriers to CPG uptake were supported with comparator studies’ findings ${ }^{11}$.

Table 3 proposes different strategies that may be employed to assist each SoC level to improve their CPG uptake into clinical practice. Through the categorisation of clinicians into different 
SoC, strategies may be developed to reach each participant at their readiness to "hear" about CPGs and to start implementing CPGs in daily practice. The authors developed "framing quotations” as possible ways that future individuals may explain their experience with and uptake of CPGs. The authors postulate that, by determining an individual's SoC and employing individualised strategies to improve CPG uptake, it will lead to more efficient and effective patient care, due to better evidence utilisation through overcoming the barrier of time.

>> Table 3: Strategies for Stages of Change levels about here>>

\section{Limitations of the study}

The authors' biases may present as potential limitations; however, these were declared at interview, during analysis and by following a rigorous research process. Due to the richness of the interview data, the authors only determined during the data analysis phase, that connecting the participants' SoC to their perception of their use of CPGs, the authors were able to expand on the understanding of the barrier of time and how it relates to the daily implementation of CPGs. The proposed model has not been tested on a larger population and further validation of the model is needed.

\section{Conclusion}

To the authors' knowledge, this is the first attempt at exploring the construct of (lack of) time for CPG uptake in relation to the PTs' readiness to behaviour change. 'Lack of time' is a commonly reported barrier in research into improving evidence uptake in professional physiotherapy practice. This study shows that 'lack of time' is a euphemism for quite different 
barriers, which map to different stages of readiness to embrace current best evidence into physiotherapy practice. For people who are not ready to change their clinical practice behaviours, statements about 'lack of time' may relate to evidence uptake being a low priority, or with lack of awareness of the need to change, or incentives to make changes. For people who are contemplating making changes to their evidence-implementing behaviours, statements about 'lack of time' may relate to perceived lack of skills and/or knowledge, concerns about how to commence a change process in their local contexts, or perceived lack of support from colleagues or management. For people who are embracing behaviour change, 'lack of time' may relate to competing priorities of learning and doing or making enough inroads into current workload to establish and maintain changed practices. Embracing and actioning evidence-informed practice is essential to improve professional practice and maintain standards. By understanding what is meant by 'lack of time', it may indicate the specific support required by physiotherapists at different stages of changing their behaviours.

\section{List of abbreviations}

CPGs: Clinical practice guidelines

EBP: Evidence-based practice

PT: Physiotherapy/ Physiotherapists

SoC: Stages of Change

TTM: Transtheoretical Model

\section{Declarations}

Conflict of interest 
The authors have no conflicts of interest to declare.

Authors' contributions

JS, YB, KG collaborated on the planning and conceptualisation of the study. JS performed the data collection. JS, YB and KG analysed the data. All authors read and approved the final manuscript.

Acknowledgements

We would like to thank all the participants of this study for participating and helping to build the field of knowledge translation in physiotherapy. This study was funded by Stellenbosch University (55956; K1811).

\section{References}

1. Treweek S, Oxman AD, Alderson P, et al. Developing and evaluating communication strategies to support informed decisions and practice based on evidence (DECIDE): protocol and preliminary results. Implement Sci. 2013;8(6).

2. Morris ZS, Wooding S, Grant J. The answer is 17 years, what is the question: understanding time lags in translational research. J R Soc Med. 2011;104(12):510-520. doi:10.1258/jrsm.2011.110180 [doi]

3. Stander J, Grimmer K, Brink Y. Training programmes to improve evidence uptake and utilisation by physiotherapists: a systematic scoping review. BMC Med Educ. 2018;18(1):14. doi:10.1186/s12909-018-1121-6

4. Committee on Quality of Health Care in America I of M. Crossing the quality chasm: a new health system for the 21st century. 2001.

This article is protected by copyright. All rights reserved. 
5. Plsek P. Institute of Medicine. Crossing the Quality Chasm: A New Health System for the 21st Century. 2001.

6. Scurlock-Evans L, Upton P, Upton D. Evidence-Based Practice in physiotherapy: a systematic review of barriers, enablers and interventions. Physiotherapy. 2014;100(3):208-219.

7. da Silva TM, Costa L da CM, Garcia AN, Costa LOP. What do physical therapists think about evidence-based practice? A systematic review. Man Ther. 2015;20(3):388401.

8. Grimshaw JM, Eccles MP, Lavis JN, Hill SJ, Squires JE. Knowledge translation of research findings. Implement Sci. 2012;7:50. doi:10.1186/1748-5908-7-50 [doi]

9. Gray M, Joy E, Plath D, Webb SA. Implementing Evidence-Based Practice. Res Soc Work Pract. 2013;23(2):157-166. doi:10.1177/1049731512467072

10. Harding KE, Porter J, Horne-Thompson A, Donley E, Taylor NF. Not Enough Time or a Low Priority? Barriers to Evidence-Based Practice for Allied Health Clinicians. J Contin Educ Health Prof. 2014;34(4):224-231. doi:10.1002/chp.21255

11. Stander J, Grimmer K, Brink Y. Factors influencing clinical practice guideline uptake by South African physiotherapists: A qualitative investigation of barriers and facilitators. J Eval Clin Pract. June 2019:jep.13182. doi:10.1111/jep.13182

12. Heiwe S, Kajermo KN, Tyni-Lenne R, et al. Evidence-based practice: attitudes, knowledge and behaviour among allied health care professionals. Int J Qual Heal Care. 2011;23(2):198-209. doi:10.1093/intqhc/mzq083

13. Prochaska JO, DiClemente CC. Transtheoretical therapy: Toward a more integrative 
model of change. Psychother Theory, Res Pract. 1982;19(3):276-288. doi:10.1037/h0088437

14. DiClemente CC, Prochaska JO. Self-change and therapy change of smoking behavior: a comparison of processes of change in cessation and maintenance. Addict Behav. 1982;7(2):133-142. http://www.ncbi.nlm.nih.gov/pubmed/7102444.

15. Di Noia J. Dietary Stages of Change and Decisional Balance: A Meta-Analytic Review. Am J Health Behav. 2010;34(5). doi:10.5993/AJHB.34.5.11

16. Hutchison AJ, Breckon JD, Johnston LH. Physical Activity Behavior Change Interventions Based on the Transtheoretical Model: A Systematic Review. Heal Educ Behav. 2009;36(5):829-845. doi:10.1177/1090198108318491

17. Srigley JA, Corace K, Hargadon DP, et al. Applying psychological frameworks of behaviour change to improve healthcare worker hand hygiene: a systematic review. $J$ Hosp Infect. 2015;91(3):202-210. doi:10.1016/j.jhin.2015.06.019

18. Prochaska JO, Redding CA, Evers KE. The Transtheoretical model and Stages of Change. In: Health Behaviour and Health Education. Fourth. San Francisco: JosseyBass; 2008:97-121.

19. O’Brien BC, Harris IB, Beckman TJ, Reed DA, Cook DA. Standards for Reporting Qualitative Research. Acad Med. 2014;89(9):1245-1251. doi:10.1097/ACM.0000000000000388

20. Mays N, Pope C, Ziebland S. Analysing qualitative data. 2006.

21. Frambach JM, van der Vleuten C, Durning SJ. AM last page: Quality criteria in qualitative and quantitative research. Acad Med. 2013;88(4):552.

This article is protected by copyright. All rights reserved. 
22. Atkins L, Francis J, Islam R, et al. A guide to using the Theoretical Domains Framework of behaviour change to investigate implementation problems. Implement Sci. 2017;12(1):77. doi:10.1186/s13012-017-0605-9

23. Cane J, O’Connor D, Michie S. Validation of the theoretical domains framework for use in behaviour change and implementation research. Implement Sci. 2012;7(1):37. doi:10.1186/1748-5908-7-37

Figure legends

Figure 1: Prochaska's Stages of Change (adapted with permission ${ }^{18}$ )

Figure 2: Process of Stages of Change allocation

Figure 3: Wheel model of time management for better CPG uptake

This article is protected by copyright. All rights reserved. 
Table 1: Classification of study participants into Stages of Change

\begin{tabular}{|c|c|c|c|c|c|c|}
\hline$\Theta$ & 苍 & $\stackrel{\mathscr{\Xi}}{\circlearrowright}$ & 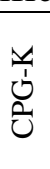 & 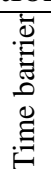 & Ü & Supporting quotation \\
\hline P01 & Pvt & 3 & 2 & $Y$ & ¿े & $\begin{array}{l}\text { "...it comes down to the education these days and less contact between the lecturers and the students... some conditions slip through that these students don't see at all... } \\
\text { they must be able to treat those conditions and so if they can read up on what are the guidelines for these conditions..." }\end{array}$ \\
\hline P02 & $\mathrm{Ed}$ & 2 & 1 & $\mathrm{~N}$ & $\ddot{Z}$ & $\begin{array}{l}\text { "I don't have much sympathy for the arguments that there isn't time. Change the narrative to not be something in addition to what you are already doing but it’s part of } \\
\text { your practice... the best clinicians in the world who are not only also loaded with patients, they still find time to attend conferences, to publish, engage with the literature, } \\
\text { develop guidelines... Are they complaining about their case load? No, they have got time so why don't you have time" }\end{array}$ \\
\hline P03 & Pvt & 1 & 2 & $Y$ & 亏ั & $\begin{array}{l}\text { "I think it does take a lot of extra effort because it is extra reading that needs to go into it and everything so it's not always during the day, it's almost forms part of an } \\
\text { extra part of the day or separate to the day's work and then doing a little bit of research and then implementing it in the clinical setting..." }\end{array}$ \\
\hline P04 & Pub & 2 & 1 & $Y$ & 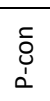 & $\begin{array}{l}\text { "I may have a very busy workload and other commitments I might only be able to do four of the five aspects of the guideline... there is a challenge when it comes to } \\
\text { workload and implementing a full guideline without hindering patient care" }\end{array}$ \\
\hline P05 & Pub & 1 & 2 & $Y$ & 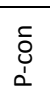 & “....in my setting I have a big load, so I won’t always use [CPGs] but I think there is a place for specific patients” \\
\hline P06 & Ed & 3 & 1 & $\mathrm{~N}$ & $\ddot{⿺}$ & $\begin{array}{l}\text { “...that would help more than just emailing someone a guideline and then they need to manoeuvre through the guideline on their own... sometimes people don’t even } \\
\text { know of the availability of guidelines and so information workshops about guidelines and the fact that guidelines need to be updated... it’s information being provided, } \\
\text { and I just need to think about how I could apply some of this. people always see something new or different as extra work...how one introduces a guideline is important...” }\end{array}$ \\
\hline P07 & Ed & 2 & 2 & $\mathrm{~N}$ & $\stackrel{0}{\varrho}$ & $\begin{array}{l}\text { "if you are sensitive when which guideline is appropriate, it could actually ease your load...but if you are only one clinician at a clinic where you have to do all the admin } \\
\text { and appointments... you don’t have time..." }\end{array}$ \\
\hline P08 & Ed & 2 & 1 & $\mathrm{D}$ & 进 & $\begin{array}{l}\text { "...I do use a clinical guideline on the management of adhesive capsulitis within a third-year case that I facilitate with the students... I'm always disappointed because they } \\
\text { don’t take up that information..." }\end{array}$ \\
\hline P09 & Ed & 3 & 1 & $\mathrm{D}$ & $\ddot{⿺}$ & "...I've never sat and worked with a guideline and worked with the patient... I’ve just checked is that in agreement with my approach..." \\
\hline P10 & Ed & 2 & 1 & $\mathrm{Y}$ & $\begin{array}{c}\text { ¿ } \\
\grave{\Lambda} \\
\text { ¿ }\end{array}$ & $\begin{array}{l}\text { "...it is much more difficult to actually have that extra time to maybe complete a health-related quality of life questionnaire. the distribution of human resources because } \\
\text { you should actually have more people where the majority of patients are... so there is a little more of equalisation. your daily interaction with your patients because as soon } \\
\text { as it can become sort of your habit of dealing with the patient, it doesn't become something like... I have to do it because management forced us to do it” }\end{array}$ \\
\hline P11 & Pvt & 2 & 2 & $\mathrm{~N}$ & 进 & "...it is very easy to go and refer to a guideline, so it was easy access to get a guideline, to Google a guideline and then apply it... in my workload" \\
\hline P12 & Pub & 3 & 1 & $\mathrm{D}$ & $\underset{\substack{0 \\
\perp}}{2}$ & $\begin{array}{l}\text { "It sort of differs because of the unexpected interruptions in my day to day work that suddenly comes from above and then I have to adjust the program. There're many } \\
\text { unplanned things coming to my table that wasn’t part of physio's plan in for today or for this week, and then you have to adjust” }\end{array}$ \\
\hline
\end{tabular}




\begin{tabular}{|c|c|c|c|c|c|c|}
\hline P13 & Pvt & 1 & 1 & D & రิ & $\begin{array}{l}\text { "I have seen people's attitude where you have, just mention the word guideline, they are like, oh, if it is big, if it looks bulky and intense and long and forms and then } \\
\text { immediately there is a negative attitude towards it. I have had that before where I have seen a guideline and I think, oh, there are so many papers to fill in. So something } \\
\text { concise, easy to use..." }\end{array}$ \\
\hline P14 & Pvt & 3 & 1 & $\mathrm{D}$ & 疍 & $\begin{array}{l}\text { "...that is very much my job, writing guidelines for clinical practice, so I think it is quite a good thing to have it, but you know, one needs to be very careful that you do not } \\
\text { become too prescriptive..." }\end{array}$ \\
\hline P15 & Pvt & 2 & 1 & $\mathrm{Y}$ & 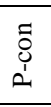 & $\begin{array}{l}\text { "I will try not to sound too negative. So guidelines are I think just generated by institutions in the first world. The issue of guideline... they tend to become prescriptive } \\
\text { rather than descriptive...I think it is going to form part of the armour because we are doing it to benchmark every now and then what the current best practice is. At the } \\
\text { moment they have become like sticks to beat people with, so if you haven't got to actually increase the range by week two post-operative then all hell breaks loose..." }\end{array}$ \\
\hline P16 & Ed & 3 & 2 & $\mathrm{~N}$ & 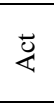 & $\begin{array}{l}\text { "...It plays a role in guiding the appropriateness of the techniques that we use and hence once you are using techniques that are tailor-made, you are definitely improving } \\
\text { the quality of care. Sometimes if they are structured, you are including spending even lesser time than you used to. Secondly, another advantage for the role that } \\
\text { guidelines play, remember, you will have maybe a maximum of an hour with a patient as a physio, so even that we are talking who is the client that we are dealing with..." }\end{array}$ \\
\hline P17 & Pvt & 2 & 1 & $\mathrm{D}$ & शें & $\begin{array}{l}\text {..."I am not fantastically good at using guidelines, so that is definitely something that I need to and have to improve on... if you have guidelines as to the type of treatment } \\
\text { that is effective at different stages, you can also explain that to a patient..." }\end{array}$ \\
\hline P18 & Pub & 2 & 1 & $\mathrm{~N}$ & 艺 & $\begin{array}{l}\text { "...physiotherapists have access to a specific file for physiotherapy in itself and then with that the physiotherapist whenever he is on the wards you can go through the } \\
\text { guidelines... You can run with the patient through it or just a guideline as a quick reference, not having to run to a book or, I mean, if you can use an APP that's even } \\
\text { better. But I mean, you don't always have the coverage for Wi-Fi... in that way we have guidelines available to us... }\end{array}$ \\
\hline P19 & Pvt & 1 & 2 & $\mathrm{Y}$ & రే & $\begin{array}{l}\text { "With the workload it can become a bit difficult to follow the guidelines. Say I have to get the patient out in a chair and you know he must be back in two hours then it's a } \\
\text { little difficult to organise your day in such a manner that you ... we travel back and forth between different hospitals, so it is very very difficult to schedule your day in } \\
\text { order to fit everything in. Most of the days it works, but it doesn't always work" }\end{array}$ \\
\hline P20 & Pvt & 2 & 2 & $\mathrm{Y}$ & $\underset{\substack{0 \\
\perp}}{2}$ & $\begin{array}{l}\text { "...if it’s going to take a lot of time it will be difficult, yes. Because we see a patient every half an hour, and half an hour before and after work for admin, I think that } \\
\text { would be a bit difficult if we are not familiar with the guidelines. One will have to first get used to them. It sounds like something that one has to look for on a computer } \\
\text { and I struggle to switch the computer on” }\end{array}$ \\
\hline P21 & Ed & 2 & 1 & $\mathrm{Y}$ & 党 & $\begin{array}{l}\text { "...If you really use it well and you follow those steps or those systematic statements in the order that it’s been given you actually realise that it helps you to use your broad } \\
\text { knowledge but to come into the specifics and to treat each patient differently..." }\end{array}$ \\
\hline P22 & Ed & 2 & 1 & $\mathrm{~N}$ & 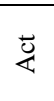 & $\begin{array}{l}\text { “...a practical way is just to engage with, even if you don’t implement the whole guideline with every single patient, but to try and think about what guideline with regards } \\
\text { to set patient, with regards to set guideline, whether there are multiple, could I try and enforce on a daily basis in my patients or in my practice, and stick to it and be good } \\
\text { about that... And then just encouraging others or making others aware of that..." }\end{array}$ \\
\hline P23 & Ed & 2 & 1 & $\mathrm{D}$ & 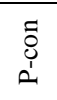 & $\begin{array}{l}\text { “...you're just trying to clear the bench, and as soon as the patients have been seen and you're shipping them off to the next institution....because you're dealing here with } \\
\text { a bench of } 60 \text { patients for the day...even workloads are so different... there’s days I saw thirty-five patients in a day, thirty-eight patients in a day and then there were days } \\
\text { I saw twelve in a day. So it would run differently on those different days” }\end{array}$ \\
\hline P24 & Pub & 1 & 1 & $\mathrm{D}$ & 营 & $\begin{array}{l}\text { "...If you really use it well and you follow those steps or those systematic statements in the order that it's been given you actually realise that it helps you to use your broad } \\
\text { knowledge but to come into the specifics and to treat each patient differently..." }\end{array}$ \\
\hline P25 & Ed & 2 & 2 & $\mathrm{D}$ & जे & $\begin{array}{l}\text { "I think within our own profession it’s possible. It also depends who you're dealing with, but it’s trickier when it now gets to kind of take this information to other } \\
\text { professions and saying look, let's go maybe tell the doctors what we're doing, or the nurses... we aren’t really doing that. I think we have one lecture that one of my staff } \\
\text { teaches to the med students, just to kind of tell them what physiotherapy is” }\end{array}$ \\
\hline P26 & Pvt & 1 & 1 & $\mathrm{D}$ & $\vec{\psi}$ & $\begin{array}{l}\text { "there's always a hiccup in the beginning and there’s always the usual little teething issues, but once we get the hang of it, it just becomes part of the flow, and you don’t } \\
\text { often think twice about it once you're used to it" }\end{array}$ \\
\hline
\end{tabular}




\begin{tabular}{|c|c|c|c|c|c|c|}
\hline P27 & Pub & 1 & 2 & D & రే & $\begin{array}{l}\text { "moderately easy to start implementing [CPGs], but it would also just be consistency... it’s easy to implement something and to start doing it, but to carry on doing it I feel } \\
\text { is often a difficult thing, especially when you're working in a place like in public where you have people coming and going... you're not always the same team..." }\end{array}$ \\
\hline P28 & Pub & 2 & 1 & $\mathrm{D}$ & نี & $\begin{array}{l}\text { “...If we are only two physios in the hospital and we have a particular number of patients in the wards, it means I might not be able to really go through whatever that I } \\
\text { have to go through because I’m rushing to see the next patient so that I can cover everything...the shortage of staff would be a barrier... if we are talking about out- } \\
\text { patients we usually manage it... so that everything can be accommodated in a day.” }\end{array}$ \\
\hline P29 & Pub & 2 & 1 & $\mathrm{~N}$ & 氶 & $\begin{array}{l}\text { "...I don't want the outcomes of treatment to be dependent on the physiotherapists themselves that are seeing the patient...I want that patient to receive the same quality of } \\
\text { care than if that patient would have been seen by a physiotherapist that specialises in that. A patient does not be at a disadvantage just because of logistical reasons..." }\end{array}$ \\
\hline P30 & Pub & 1 & 1 & $\mathrm{D}$ & $\underset{\substack{0 \\
\perp}}{2}$ & $\begin{array}{l}\text { "If the guidelines can make my life easier then it will be easy but if the guidelines will be a very lengthy process then it will make it challenging. I think especially in our } \\
\text { setting, I work in a government institution and it's the age-old thing of being short-staffed but for example, we can't see a patient twice a day. I can't guarantee that I will } \\
\text { be able to see a patient twice a day where in a private institution that is almost the norm... I think if guidelines caused me to take more time with my patients, that will be } \\
\text { really difficult to implement because I still have twenty others also to see" }\end{array}$ \\
\hline P31 & Pub & 1 & 1 & $\mathrm{D}$ & 蔗 & $\begin{array}{l}\text { "Technically it should make my clinical load easier because if I have a guideline to work upon, it's something that should make seeing patients sort of easier...but } \\
\text { sometimes I do feel like time wise, I don't know, maybe for example you don't have time to do ten repetitions times three sets for the patient and so you show them all the } \\
\text { exercise but you only do one set and then you show them how to walk." }\end{array}$ \\
\hline
\end{tabular}

Key: ID=Participant identifier; Years=Years in practice; CPG-K=CPG knowledge; SOC=Stage of change; Pub=Public; Pvt=Private; Ed=Education; Y=Agree; N=Disagree; D=Do not know; P-con=Pre-contemplation; Prep=Preparation; Con=Contemplation; Act=Action; Main=Maintenance

Years in practice: $0-10=1 ; 11-20=2 ; 21+=3$. CPG knowledge: $1=$ Understand concept of CPGs; $2=$ Does not understand concept of CPGs

Table 2: Mapping of wheel model to Theoretical Domains Framework 22

\begin{tabular}{|l|l|l|l|}
\hline TDF Domains (Definition) & $\begin{array}{l}\text { Wheel } \\
\text { circle(s) }\end{array}$ & Circle construct(s) & Rationale \\
\hline 1. Knowledge (An awareness of the existence of something) & $\begin{array}{l}\text { Time } \\
\text { subthemes }\end{array}$ & CPG knowledge & $\begin{array}{l}\text { Level of knowledge on what are CPGs will influence their CPG-uptake in } \\
\text { practice. }\end{array}$ \\
\hline $\begin{array}{l}\text { 2. Skills (An ability or proficiency acquired through } \\
\text { practice) }\end{array}$ & $\begin{array}{l}\text { Time } \\
\text { subthemes }\end{array}$ & Accessing CPGs & $\begin{array}{l}\text { The ability to access CPGs directly influences the individual's willingness } \\
\text { to use CPGs in practice }\end{array}$ \\
\hline $\begin{array}{l}\text { 3. Social/professional role and identity (A coherent set of } \\
\text { behaviours and displayed personal qualities of an individual } \\
\text { in a social or work setting) }\end{array}$ & $\begin{array}{l}\text { Time } \\
\text { subthemes }\end{array}$ & Few staff, high load & $\begin{array}{l}\text { If the individual feels limited in their time availability to use CPGs, due to } \\
\text { limited staff and high workload, it will affect their willingness for CPG- } \\
\text { uptake. }\end{array}$ \\
\hline $\begin{array}{l}\text { 4. Beliefs about capabilities (Acceptance of the truth, reality } \\
\text { or validity about an ability, talent or facility that a person } \\
\text { can put to constructive use) }\end{array}$ & $\begin{array}{l}\text { Time } \\
\text { subthemes }\end{array}$ & $\begin{array}{l}\text { CPG knowledge \& } \\
\text { accessing of CPG }\end{array}$ & $\begin{array}{l}\text { Changing perceptions about CPG knowledge and accessing CPGs, may } \\
\text { change CPG-uptake behaviour in practice. }\end{array}$ \\
\hline $\begin{array}{l}\text { 5. Optimism (The confidence that things will happen for the } \\
\text { best or that desired goals will be attained) } \\
\text { Optimism/ Pessimism/ Unrealistic optimism/ Identity }\end{array}$ & $\begin{array}{l}\text { EBP as } \\
\text { priority }\end{array}$ & $\begin{array}{l}\text { Observing EBP as priority in practice may be related to an optimism } \\
\text { towards its use in practice but need to be facilitated to prevent a negative } \\
\text { (pessimistic) outlook towards the seeming "burden” of more to do in } \\
\text { practice. }\end{array}$ \\
\hline
\end{tabular}


Time as a barrier to evidence uptake

\begin{tabular}{|c|c|c|c|}
\hline $\begin{array}{l}\text { 6. Beliefs about Consequences (Acceptance of the truth, } \\
\text { reality, or validity about outcomes of a behaviour in a given } \\
\text { situation) }\end{array}$ & $\begin{array}{l}\text { Quality } \\
\text { criteria }\end{array}$ & & $\begin{array}{l}\text { The quality criteria of healthcare are directly affected by the (dis)use of } \\
\text { CPGs to inform clinical decision-making. }\end{array}$ \\
\hline $\begin{array}{l}\text { 7. Reinforcement (Increasing the probability of a response } \\
\text { by arranging a dependent relationship, or contingency, } \\
\text { between the response and a given stimulus) }\end{array}$ & $\begin{array}{l}\text { Stages of } \\
\text { change }\end{array}$ & & $\begin{array}{l}\text { Moving through the stages of change, particularly advancing through it, } \\
\text { contributes to reinforcement of the use and applicability of CPGs in } \\
\text { practice. }\end{array}$ \\
\hline $\begin{array}{l}\text { 8. Intentions (A conscious decision to perform a behaviour } \\
\text { or a resolve to act in a certain way) }\end{array}$ & $\begin{array}{l}\text { Stages of } \\
\text { change }\end{array}$ & & $\begin{array}{l}\text { Moving through the stages of change will be both a conscious and } \\
\text { unconscious process. }\end{array}$ \\
\hline $\begin{array}{l}\text { 9. Goals (Mental representations of outcomes or end states } \\
\text { that an individual wants to achieve) }\end{array}$ & $\begin{array}{l}\text { Quality } \\
\text { criteria; Time } \\
\text { subthemes }\end{array}$ & Time is money & $\begin{array}{l}\text { The quality criteria of healthcare are directly affected by the (dis)use of } \\
\text { CPGs to inform clinical decision-making. CPG-use can affect monetary } \\
\text { compensation }\end{array}$ \\
\hline $\begin{array}{l}\text { 10. Memory, attention and decision processes (The ability to } \\
\text { retain information, focus selectively on aspects of the } \\
\text { environment and choose between two/ more alternatives) }\end{array}$ & $\begin{array}{l}\text { Quality } \\
\text { criteria; Time } \\
\text { subthemes }\end{array}$ & $\begin{array}{l}\text { CPG knowledge \& } \\
\text { accessing of CPG }\end{array}$ & $\begin{array}{l}\text { Changing abilities of CPG knowledge and accessing CPGs, may change } \\
\text { CPG-uptake behaviour in practice, affecting adherence to quality criteria of } \\
\text { healthcare. }\end{array}$ \\
\hline $\begin{array}{l}\text { 11. Environmental context and resources (Any circumstance } \\
\text { of a person's situation or environment that discourages or } \\
\text { encourages the development of skills and abilities, } \\
\text { independence, social competence and adaptive behaviour) }\end{array}$ & $\begin{array}{l}\text { Whole wheel } \\
\text { model }\end{array}$ & & $\begin{array}{l}\text { The wheel model relates directly to the context of the individual's process } \\
\text { of time management to address and overcome lack of time subthemes and } \\
\text { moving through stages of change to conform to quality criteria of } \\
\text { healthcare. }\end{array}$ \\
\hline $\begin{array}{l}\text { 12. Social influences (Those interpersonal processes that } \\
\text { can cause individuals to change their thoughts, feelings, or } \\
\text { behaviours) }\end{array}$ & $\begin{array}{l}\text { Stages of } \\
\text { change; Time } \\
\text { subthemes }\end{array}$ & $\begin{array}{l}\text { Time is money; Few } \\
\text { staff, high load }\end{array}$ & $\begin{array}{l}\text { The two-time subthemes relate to how an individual perceives the } \\
\text { usefulness of CPG-uptake in their working environment and the perception } \\
\text { may influence their ability to move through the stages of change to change } \\
\text { their CPG-uptake behaviour. }\end{array}$ \\
\hline $\begin{array}{l}\text { 13. Emotion (A complex reaction pattern, involving } \\
\text { experiential, behavioural, and physiological elements, by } \\
\text { which the individual attempts to deal with a personally } \\
\text { significant matter or event) }\end{array}$ & $\begin{array}{l}\text { EBP as } \\
\text { priority; } \\
\text { Quality } \\
\text { criteria }\end{array}$ & & $\begin{array}{l}\text { Adhering to the quality criteria of healthcare and delivering patient-centred } \\
\text { care through evidence-informed practice behaviours affects how the } \\
\text { individual perceive their role as a healthcare professional. }\end{array}$ \\
\hline $\begin{array}{l}\text { 14. Behavioural regulation (Anything aimed at managing } \\
\text { changing objectively observed or measured actions) }\end{array}$ & $\begin{array}{l}\text { Stages of } \\
\text { change }\end{array}$ & & $\begin{array}{l}\text { Moving through the stages of change will be both a conscious and } \\
\text { unconscious process. }\end{array}$ \\
\hline
\end{tabular}


Table 3: Strategies for SoC levels

\begin{tabular}{|c|c|c|}
\hline SoC & Framing quotation & Strategy \\
\hline $\begin{array}{l}\text { Pre- } \\
\text { con }\end{array}$ & $\begin{array}{l}\text { "I don’t know what CPGs are } \\
\text { and I don't understand why I } \\
\text { should engage with them” }\end{array}$ & $\begin{array}{l}\text { Educate about CPGs (what they look like, } \\
\text { overview of how they are developed, quality } \\
\text { criteria) }\end{array}$ \\
\hline Con & $\begin{array}{l}\text { "I've heard of CPGs, but it } \\
\text { seems like so much work to } \\
\text { engage with them, I am not } \\
\text { convinced, and I don't know } \\
\text { where to start" }\end{array}$ & $\begin{array}{l}\text { Educate about what a CPG is, how and where to } \\
\text { find them, give some evidence of how CPG } \\
\text { implementation has made significant changes in } \\
\text { other practices (feel good stories about lives } \\
\text { saved or disease reduced etc); and how adoption } \\
\text { of a recommendation could prevent inefficiency } \\
\text { and ineffective practice }\end{array}$ \\
\hline Prep & $\begin{array}{l}\text { "I've heard of CPGs and I } \\
\text { would like to start using them } \\
\text { in practice. Where do I } \\
\text { start?" }\end{array}$ & $\begin{array}{l}\text { Educate on choosing CPGs (quality, recency, } \\
\text { answers to clinical question), how to prioritise } \\
\text { conditions seen in practice for application of } \\
\text { CPGs (difficult to treat, variable outcomes, } \\
\text { prevalent, costly) }\end{array}$ \\
\hline Action & $\begin{array}{l}\text { "I have used CPGs a few } \\
\text { times, but not sure if I am } \\
\text { using them effectively. How } \\
\text { do I optimise my use of } \\
\text { CPGs?" }\end{array}$ & $\begin{array}{l}\text { Educate on strength of recommendations and how } \\
\text { this links with making practice decisions } \\
\text { (including wording linked to strength of } \\
\text { evidence), how this relates to own clinical } \\
\text { practice (evidence-practice gaps); identifying } \\
\text { strategies to put CPGs into own practice; use of } \\
\text { outcome measures }\end{array}$ \\
\hline Main & $\begin{array}{l}\text { "I am already putting CPGs } \\
\text { into practice. What's next?" }\end{array}$ & $\begin{array}{l}\text { Become a change agent to put CPGs into practice } \\
\text { on a broader scale (guideline champion); } \\
\text { reflective practice; use of outcome measures; } \\
\text { publication; speaking at meetings }\end{array}$ \\
\hline
\end{tabular}




\begin{tabular}{|c|c|}
\hline http://www.equator-network.org/reporting-guidelines/srqr/ & P./line \\
\hline \multicolumn{2}{|l|}{ Title and abstract } \\
\hline $\begin{array}{l}\text { Title - Concise description of the nature and topic of the study Identifying the study as qualitative or } \\
\text { indicating the approach (e.g., ethnography, grounded theory) or data collection methods (e.g., } \\
\text { interview, focus group) is recommended }\end{array}$ & $\mathrm{Y} / 1$ \\
\hline $\begin{array}{l}\text { Abstract - Summary of key elements of the study using the abstract format of the intended } \\
\text { publication; typically includes background, purpose, methods, results, and conclusions }\end{array}$ & $\mathrm{Y} / 2$ \\
\hline \multicolumn{2}{|l|}{ Introduction } \\
\hline \begin{tabular}{|l} 
Problem formulation - Description and significance of the problem/phenomenon studied; review of \\
relevant theory and empirical work; problem statement \\
\end{tabular} & $\mathrm{Y} / 3-4$ \\
\hline Purpose or research question - Purpose of the study and specific objectives or questions & Y/4-5 \\
\hline \multicolumn{2}{|l|}{ Methods } \\
\hline $\begin{array}{l}\text { Qualitative approach and research paradigm - Qualitative approach (e.g., ethnography, grounded } \\
\text { theory, case study, phenomenology, narrative research) \& guiding theory if appropriate; identifying } \\
\text { research paradigm (e.g., postpositivist, constructivist/ interpretivist) is also recommended; rationale }\end{array}$ & Y/5-6 \\
\hline $\begin{array}{l}\text { Researcher characteristics and reflexivity - Researchers' characteristics that may influence the } \\
\text { research, including personal attributes, qualifications/experience, relationship with participants, } \\
\text { assumptions, and/or presuppositions; potential or actual interaction between researchers' } \\
\text { characteristics and the research questions, approach, methods, results, and/or transferability }\end{array}$ & Y/6 \\
\hline Context - Setting/site and salient contextual factors; rationale** & Y/6-8 \\
\hline $\begin{array}{l}\text { Sampling strategy - How and why research participants, documents, or events were selected; criteria } \\
\text { for deciding when no further sampling was necessary (e.g., sampling saturation); rationale }\end{array}$ & $\mathrm{Y} / 5$ \\
\hline $\begin{array}{l}\text { Ethical issues pertaining to human subjects - Documentation of approval by an appropriate ethics } \\
\text { review board and participant consent, or explanation for lack thereof; other confidentiality and data } \\
\text { security issues }\end{array}$ & $\mathrm{Y} / 5$ \\
\hline $\begin{array}{l}\text { Data collection methods - Types of data collected; details of data collection procedures including (as } \\
\text { appropriate) start and stop dates of data collection and analysis, iterative process, triangulation of } \\
\text { sources/methods, and modification of procedures in response to evolving study findings; rationale** }\end{array}$ & $\mathrm{Y} / 5$ \\
\hline $\begin{array}{l}\text { Data collection instruments and technologies - Description of instruments (e.g., interview guides, } \\
\text { questionnaires) \& devices used for data collection; if/how instrument(s) changed over course of study }\end{array}$ & $\mathrm{Y} / 5$ \\
\hline $\begin{array}{l}\text { Units of study - Number and relevant characteristics of participants, documents, or events included in } \\
\text { the study; level of participation (could be reported in results) }\end{array}$ & Y/5-6 \\
\hline $\begin{array}{l}\text { Data processing - Methods for processing data prior to and during analysis, including transcription, } \\
\text { data entry, data management and security, verification of data integrity, data coding, and } \\
\text { anonymization/de-identification of excerpts }\end{array}$ & $\mathrm{Y} / 5$ \\
\hline $\begin{array}{l}\text { Data analysis - Process by which inferences, themes, etc., were identified and developed, including } \\
\text { the researchers involved in data analysis; usually references a specific paradigm/ approach; rationale }\end{array}$ & Y/6-7 \\
\hline $\begin{array}{l}\text { Techniques to enhance trustworthiness - Techniques to enhance trustworthiness and credibility of } \\
\text { data analysis (e.g., member checking, audit trail, triangulation); rationale** }\end{array}$ & Y/6 \\
\hline \multicolumn{2}{|l|}{ Results/findings } \\
\hline $\begin{array}{l}\text { Synthesis and interpretation - Main findings (e.g., interpretations, inferences, and themes); might } \\
\text { include development of a theory or model, or integration with prior research or theory }\end{array}$ & Y/7-9 \\
\hline $\begin{array}{l}\text { Links to empirical data - Evidence (e.g., quotations, field notes, text excerpts, photographs) to } \\
\text { substantiate analytic findings }\end{array}$ & $\begin{array}{l}\text { Y/ } \\
\text { Table1 }\end{array}$ \\
\hline
\end{tabular}

Discussion 
Integration with prior work, implications, transferability, and contribution(s) to the field - Short summary of main findings; explanation of how findings and conclusions connect to, support, elaborate on, or challenge conclusions of earlier scholarship; discussion of scope of application/generalizability; identification of unique contribution(s) to scholarship in a discipline or field

Limitations - Trustworthiness and limitations of findings

Other

Conflicts of interest - Potential sources of influence or perceived influence on study conduct and conclusions; how these were managed

Funding - Sources of funding/ support; funders role in data collection, interpretation, and reporting 


\section{University Library}

\section{- M I I N E R VA \\ A gateway to Melbourne's research publications}

Minerva Access is the Institutional Repository of The University of Melbourne

Author/s:

Stander, J;Grimmer, K;Brink, Y

Title:

Time as a barrier to evidence uptake-A qualitative exploration of the concept of time for clinical practice guideline uptake by physiotherapists

Date:

2020-04-16

Citation:

Stander, J., Grimmer, K. \& Brink, Y. (2020). Time as a barrier to evidence uptake-A qualitative exploration of the concept of time for clinical practice guideline uptake by physiotherapists. Journal of Evaluation in Clinical Practice, 27 (2), pp.280-290. https:// doi.org/10.1111/jep.13397.

Persistent Link:

http://hdl.handle.net/11343/275649 